\title{
Frontal Ring-Opening Metathesis Copolymerization: Deviation of Front Velocity from Mixing Rules
}

\author{
Huiying Liu ${ }^{\mathrm{a}, \mathrm{b}}$, Haibing Wei ${ }^{\mathrm{a}}$, Jeffrey S. Moore ${ }^{\mathrm{a}, \mathrm{b}^{*}}$ \\ ${ }^{a}$ Department of Chemistry, University of Illinois at Urbana-Champaign, Urbana, Illinois 61801, \\ USA. \\ b Beckman Institute of Advanced Science and Technology, University of Illinois at Urbana- \\ Champaign, Urbana, Illinois 61801, USA.
}

*To whom all correspondence should be addressed. Phone: (217) 244-4024.

Fax: (217) 244-8068. E-mail: jsmoore @illinois.edu

\section{Table of Contents}

I. General Experimental Details.................................................................. 2

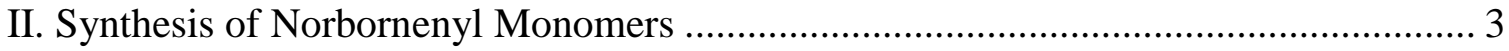

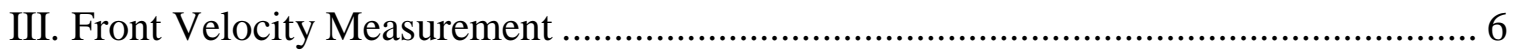

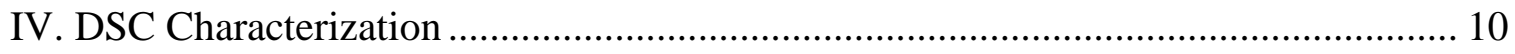

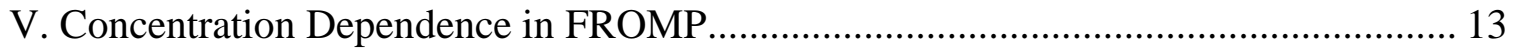

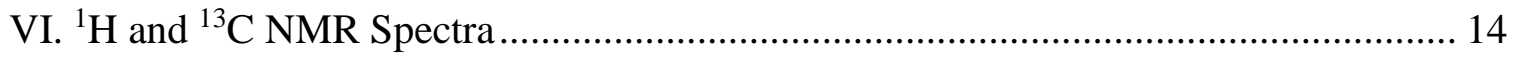

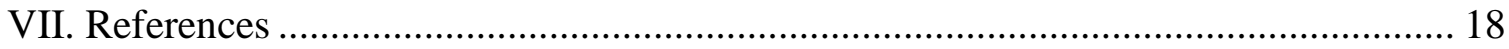




\section{General Experimental Details}

Unless otherwise stated, all starting materials and reagents such as endo-dicyclopentadiene (endoDCPD), 5-ethylidene-2-norbornene (ENB), exo-5-norbornenecarboxylic acid (exo-NBE-COOH) and second-generation Grubbs' catalyst (Grubbs II), and tributylphosphite were purchased from Sigma-Aldrich without further purification. Since endo-DCPD is a solid at room temperature, 5 wt. \% ENB was added to depress the melting point. All references to endo-DCPD herein refer to the 95:5 endo-DCPD:ENB solution. ${ }^{1} \mathrm{H}$ and ${ }^{13} \mathrm{C}$ NMR spectra were recorded on a Varian Unity $500 \mathrm{MHz}$ spectrometer or a Carver B500 spectrometer in the VOICE NMR laboratory at the University of Illinois. Chemical shifts are reported in $\delta(\mathrm{ppm})$ relative to the residual solvent peak

$\left(\mathrm{CDCl}_{3}: 7.26\right.$ for ${ }^{1} \mathrm{H} ; \mathrm{CDCl}_{3}: 77.16$ for $\left.{ }^{13} \mathrm{C}\right)$. Coupling constants $(J)$ are reported in Hertz $(\mathrm{Hz})$. Splitting patterns are designated as s (singlet), d (doublet), $\mathrm{t}$ (triplet), quint (quintet), sep (septet), dd (doublet of doublets), dt (doublet of triplets), and m (multiplet). High-resolution EI/ESI mass spectra were recorded on a Micromass 70-VSE spectrometer through the Mass Spectrometry Facility, SCS at University of Illinois. The DSC measurement was performed using TA Instrument Q20 Differential Scanning Calorimeter equipped with a Liquid Nitrogen Cooling System (LNCS). Tzero hermetic aluminum pans and lids were used as sample testing containers. Nitrogen was used as sample purge gas and the ramping rate was $10{ }^{\circ} \mathrm{C} / \mathrm{min}$. Front temperatures were measured using stainless steel type T thermocouples (Omega Engineering, Model TMQSS-020U). Thermocouple data was collected using a temperature sensor (Phidgets, Model 1048) and recorded using a custom LabVIEW code (National Instruments) at $100 \mathrm{~Hz}$. 


\section{Synthesis of Norbornenyl Monomers}

exo-Methyl 5-norbornene-2-carboxylate (exo-NBE-COOMe)

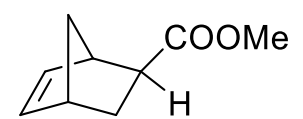

In a solution of exo-NBE-COOH (2.5 g, $18 \mathrm{mmol}, 1.0$ equiv.) in $\mathrm{CH}_{2} \mathrm{Cl}_{2}$ (2.5 $\mathrm{mL})$, methanol (7.5 mL, 10 equiv.) and $\mathrm{H}_{2} \mathrm{SO}_{4}(0.25 \mathrm{~mL})$ were added. The reaction was allowed to stir at $70{ }^{\circ} \mathrm{C}$. After the completion of the reaction monitored by TLC, the resulting mixture was concentrated. $\mathrm{CH}_{2} \mathrm{Cl}_{2}(20 \mathrm{~mL})$ was added to the residue and washed with brine $(2 \times 15 \mathrm{~mL})$, dried with anhydrous sodium sulfate, and then concentrated. The crude product was further purified by flash chromatography to give the desired compound as a colorless liquid $(2.53 \mathrm{~g}, 92 \%) .{ }^{1} \mathrm{H} \mathrm{NMR}$ $\left(\mathrm{CDCl}_{3}, 500 \mathrm{MHz}\right) \delta 6.14(\mathrm{dd}, J=5.5 \mathrm{~Hz}$ and $3 \mathrm{~Hz}, 1 \mathrm{H}), 6.10(\mathrm{dd}, J=5.5 \mathrm{~Hz}$ and $3 \mathrm{~Hz}, 1 \mathrm{H})$, $3.69(\mathrm{~s}, 3 \mathrm{H}), 3.04(\mathrm{~s}, 1 \mathrm{H}), 2.92(\mathrm{~s}, 1 \mathrm{H}), 2.23(\mathrm{dd}, J=10.5 \mathrm{~Hz}$ and $4.5 \mathrm{~Hz}, 1 \mathrm{H}), 1.92(\mathrm{dt}, J=11.5$ $\mathrm{Hz}$ and $4 \mathrm{~Hz}, 1 \mathrm{H}), 1.52(\mathrm{~d}, J=8.5 \mathrm{~Hz}, 1 \mathrm{H}), 1.39-1.34(\mathrm{~m}, 2 \mathrm{H}) ;{ }^{13} \mathrm{C} \mathrm{NMR}\left(\mathrm{CDCl}_{3}, 125 \mathrm{MHz}\right) \delta$ 176.9, 138.2, 135.9, 51.9, 46.7, 46.5, 43.1, 41.8, 30.5. HRMS-EI $(m / z)$ : calculated for $\mathrm{C}_{9} \mathrm{H}_{12} \mathrm{O}_{2}$ $[\mathrm{M}]^{+}, 152.0837$; Found, 152.0833.

\section{exo-5-(methoxymethyl)bicyclo[2.2.1]hept-2-ene (exo-NBE-CH2OMe)}

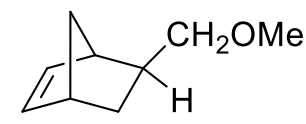

exo-NBE-COOMe was synthesized in two steps following previously published procedures: reduction of exo-NBE-COOH $(5 \mathrm{~g})$ with $\mathrm{LiAlH}_{4}$ and methylation of the resulting exo-5-norbornene-2-methanol (exo-NBE- $\left.\mathrm{CH}_{2} \mathrm{OH}\right){ }^{1,2}$ The final product was further purified by flash chromatography to give the desired compound as a colorless liquid ( $2.7 \mathrm{~g}$, twostep yield 54\%). ${ }^{1} \mathrm{H} \mathrm{NMR}\left(\mathrm{CDCl}_{3}, 500 \mathrm{MHz}\right) \delta 6.10(\mathrm{dd}, J=5.5 \mathrm{~Hz}$ and $2.5 \mathrm{~Hz}, 1 \mathrm{H}), 6.05(\mathrm{dd}, J$ $=5.5 \mathrm{~Hz}$ and $2.5 \mathrm{~Hz}, 1 \mathrm{H}), 3.42(\mathrm{dd}, J=9.5 \mathrm{~Hz}$ and $6 \mathrm{~Hz}, 1 \mathrm{H}), 3.36(\mathrm{~s}, 3 \mathrm{H}), 3.30(\mathrm{t}, J=9 \mathrm{~Hz}, 1$ H), $2.81(\mathrm{~s}, 1 \mathrm{H}), 2.73(\mathrm{~s}, 1 \mathrm{H}), 1.68(\mathrm{sep}, J=5 \mathrm{~Hz}, 1 \mathrm{H}), 1.34-1.22(\mathrm{~m}, 3 \mathrm{H}), 1.11(\mathrm{dt}, J=12 \mathrm{~Hz}$ 
and $3.5 \mathrm{~Hz}, 1 \mathrm{H}) ;{ }^{13} \mathrm{C} \mathrm{NMR}\left(\mathrm{CDCl}_{3}, 125 \mathrm{MHz}\right) \delta$ 136.8, 136.7, 77.8, 58.9, 45.2, 43.8, 41.7, 39.0, 29.8. HRMS-EI $(\mathrm{m} / \mathrm{z})$ : calculated for $\mathrm{C}_{9} \mathrm{H}_{14} \mathrm{O}[\mathrm{M}]^{+}, 138.1045$; Found, 138.1043.

Synthesis of dinorbornenyl cross-linkers: These exo, exo-cross-linkers were obtained through two steps, converting exo-NBE-COOH to acyl chloride, followed by nucleophilic addition of the corresponding alcohol. Under $\mathrm{N}_{2}$ atmosphere, $4 \mathrm{~mL}$ oxalyl chloride was added to exo-NBE-COOH (2.5 g, 1.05 equiv.). After complete dissolution of the solids, two drops of anhydrous DMF was added. The reaction was allowed to stir overnight at room temperature. The mixture was then concentrated by rotary evaporator to remove excess amount of oxalyl chloride. $\mathrm{CHCl}_{3}(3 \mathrm{~mL})$ was added to the residue and concentrated again. This was repeated three times to remove as much oxalyl chloride as possible. The resulting crude exo-NBE-COCl (yellowish oil) was dissolved in $20 \mathrm{~mL} \mathrm{CH}_{2} \mathrm{Cl}_{2}$ and placed in an ice bath. A solution of alcohol (1.0 equiv. exo- $\mathrm{NBE}-\mathrm{CH}_{2} \mathrm{OH}$ for CL1 and 0.5 equiv. diol for $\mathbf{C L 2} \& \mathbf{C L 3}$ ) and $\mathrm{NEt}_{3}$ (1.2 equiv.) in $10 \mathrm{~mL} \mathrm{CH}_{2} \mathrm{Cl}_{2}$ was added. The reaction was warmed to room temperature and stirred under $\mathrm{N}_{2}$ for 4 hours. TLC analyses indicated the reaction to be complete. The reaction mixture was extracted with $\mathrm{CH}_{2} \mathrm{Cl}_{2}$ and brine, dried with anhydrous sodium sulfate, and then concentrated. The crude product was purified by flash chromatography to give the desired compound as a colorless liquid.

\section{CL1}

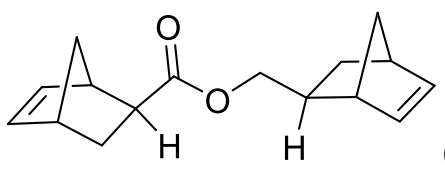

Colorless liquid (3.8 g, 90\%). ${ }^{1} \mathrm{H} \mathrm{NMR}\left(\mathrm{CDCl}_{3}, 500 \mathrm{MHz}\right) \delta 6.15-6.07$ (m, $4 \mathrm{H}), 4.18-4.13(\mathrm{~m}, 1 \mathrm{H}), 4.00(\mathrm{dt}, J=10.5 \mathrm{~Hz}$ and $9 \mathrm{~Hz}, 1 \mathrm{H}), 3.05(\mathrm{~s}, 1 \mathrm{H}), 2.93(\mathrm{~s}, 1 \mathrm{H}), 2.84$ (s, $1 \mathrm{H}), 2.70(\mathrm{~s}, 1 \mathrm{H}), 2.24(\mathrm{dd}, J=10 \mathrm{~Hz}$ and $4.5 \mathrm{~Hz}, 1 \mathrm{H}), 1.94(\mathrm{dt}, J=12 \mathrm{~Hz}$ and $4 \mathrm{~Hz}, 1 \mathrm{H})$, 1.77-1.71 (m, $1 \mathrm{H}), 1.54(\mathrm{~d}, J=9 \mathrm{~Hz}, 1 \mathrm{H}), 1.40-1.26(\mathrm{~m}, 5 \mathrm{H}), 1.18(\mathrm{dt}, J=12 \mathrm{~Hz}$ and $4 \mathrm{~Hz}, 1 \mathrm{H})$; 
${ }^{13} \mathrm{C}$ NMR $\left(\mathrm{CDCl}_{3}, 125 \mathrm{MHz}\right) \delta 176.5,138.2,137.1,136.4,135.9,68.7,46.8,46.5,45.1,43.8,43.4$, 41.8, 41.7, 38.2, 30.5, 29.7. HRMS-EI $(\mathrm{m} / z)$ : calculated for $\mathrm{C}_{16} \mathrm{H}_{20} \mathrm{O}_{2}[\mathrm{M}]^{+}, 244.1463$; Found, 244.1473.

\section{CL2}<smiles>O=C(OCCOC(=O)C1CC2C=CC1C2)C1CC2C=CC1C2</smiles>

Colorless liquid (1.6 g, 61\%). ${ }^{1} \mathrm{H}$ NMR $\left(\mathrm{CDCl}_{3}, 500 \mathrm{MHz}\right) \delta$ $6.14(\mathrm{dd}, J=5.5 \mathrm{~Hz}$ and $2.5 \mathrm{~Hz}, 2 \mathrm{H}), 6.10(\mathrm{dd}, J=5.5 \mathrm{~Hz}$ and $2.5 \mathrm{~Hz}, 2 \mathrm{H}), 4.35-4.27(\mathrm{~m}, 4 \mathrm{H})$, $3.04(\mathrm{~s}, 2 \mathrm{H}), 2.92(\mathrm{~s}, 2 \mathrm{H}), 2.24(\mathrm{dd}, J=10 \mathrm{~Hz}$ and $4 \mathrm{~Hz}, 2 \mathrm{H}), 1.92(\mathrm{dt}, J=12 \mathrm{~Hz}$ and $4 \mathrm{~Hz}, 2 \mathrm{H})$, $1.51(\mathrm{~d}, J=8 \mathrm{~Hz}, 2 \mathrm{H}), 1.39-1.34(\mathrm{~m}, 4 \mathrm{H}) ;{ }^{13} \mathrm{C} \mathrm{NMR}\left(\mathrm{CDCl}_{3}, 125 \mathrm{MHz}\right) \delta 176.1,138.3,135.8$, 62.3, 46.8, 46.5, 43.2, 41.8, 30.5. HRMS-ESI $(\mathrm{m} / \mathrm{z})$ : calculated for $\mathrm{C}_{18} \mathrm{H}_{22} \mathrm{O}_{4} \mathrm{Na}[\mathrm{M}+\mathrm{Na}]^{+}$, 325.1416; Found, 325.1411.

\section{CL3}

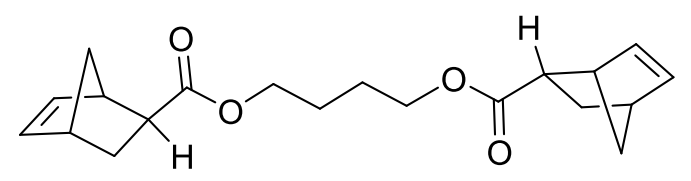

Colorless liquid $(1.7 \mathrm{~g}, 60 \%) .{ }^{1} \mathrm{H}$ NMR $\left(\mathrm{CDCl}_{3}, 500\right.$ MHz) $\delta 6.13(\mathrm{dd}, J=5.5 \mathrm{~Hz}$ and $3 \mathrm{~Hz}, 2 \mathrm{H}), 6.10(\mathrm{dd}, J=5.5 \mathrm{~Hz}$ and $3 \mathrm{~Hz}, 2 \mathrm{H}), 4.12(\mathrm{~s}, 4 \mathrm{H})$, $3.03(\mathrm{~s}, 2 \mathrm{H}), 2.92(\mathrm{~s}, 2 \mathrm{H}), 2.22(\mathrm{dd}, J=9.5 \mathrm{~Hz}$ and $4.5 \mathrm{~Hz}, 2 \mathrm{H}), 1.91(\mathrm{dt}, J=11.5 \mathrm{~Hz}$ and $4 \mathrm{~Hz}$, $2 \mathrm{H}), 1.73$ (quint, $J=3 \mathrm{~Hz}, 4 \mathrm{H}), 1.51(\mathrm{~d}, J=8.5 \mathrm{~Hz}, 2 \mathrm{H}), 1.39-1.34(\mathrm{~m}, 4 \mathrm{H}) ;{ }^{13} \mathrm{C} \mathrm{NMR}\left(\mathrm{CDCl}_{3}\right.$, $125 \mathrm{MHz}) \delta 176.4,138.2,135.9,64.1,46.8,46.5,43.3,41.8,30.5,25.6$. HRMS-ESI $(\mathrm{m} / \mathrm{z})$ : calculated for $\mathrm{C}_{20} \mathrm{H}_{27} \mathrm{O}_{4}[\mathrm{M}+\mathrm{H}]^{+}, 331.1909$; Found, 331.1913. 


\section{Front Velocity Measurement}

Homopolymerization: Instead of $13 \times 100 \mathrm{~mm}$ test tubes as reported in previous examples, we performed all FROMP experiments in NMR tubes (Economy $5 \mathrm{~mm} \times 7$ " L, $100 \mathrm{MHz}$ ) in this study. The front velocities $\left(v_{f}\right)$ obtained with NMR tubes are the same or slightly lower (especially for less reactive monomers) compared to those obtained in test tubes. The formulation is Grubbs II (100 ppm per norbornenyl double bond), 1.0 equiv. $\mathrm{P}(\mathrm{OBu})_{3}$ per mole ruthenium (dissolved in 40 $\mu \mathrm{L}$ dry toluene) and $500 \mathrm{mg}$ neat liquid monomers. The catalyst/phosphite solution was freshly made and then added to $500 \mathrm{mg}$ monomers. After thoroughly mixing and rapidly transferring to an NMR tube, a soldering iron was applied near the surface of the liquid. FROMP proceeded in a descending mode with the thermocouple positioned roughly $1 \mathrm{~cm}$ from the top of the liquid surface. Once frontal propagation started, the soldering iron was removed. $v_{f}$ was calculated from the slope of the linear fitting of the front position against time. To avoid $v_{f}$ acceleration introduced by the thermocouple on propagation, $v_{f}$ calculations only included the region without the thermocouple.

Copolymerization: The total mass of monomers was kept at $500 \mathrm{mg}$, and the procedure and formulation are the same as homopolymerization. 

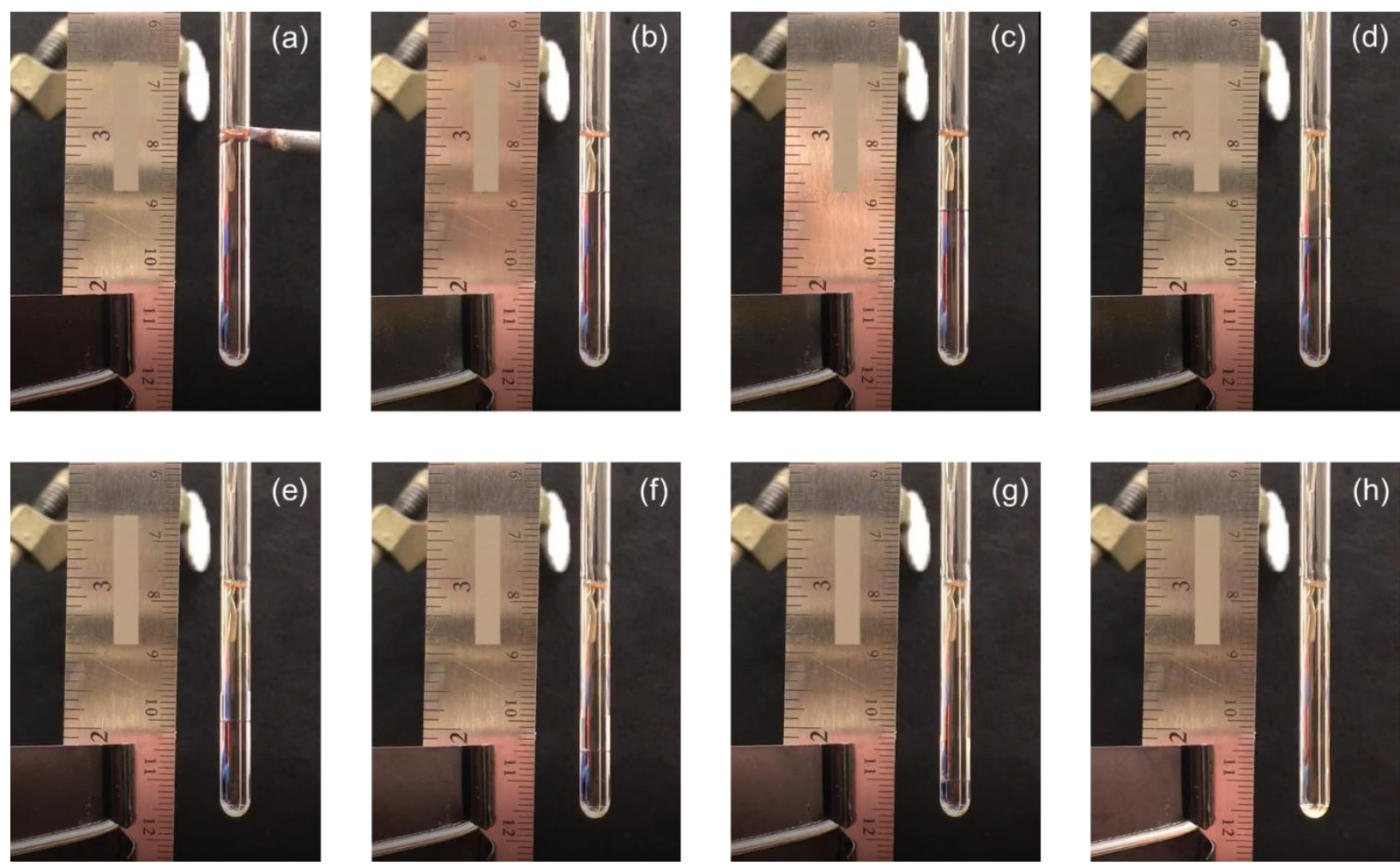

Scheme S1. FROMP copolymerization of endo-DCPD and CL1 (40 wt. \% loading). (a) FROMP initiated by applying a soldering iron to the outside of the tube near the surface of the solution. (b) The point where maximum front temperature was recorded. (c)-(h) The region where $v_{f}$ was measured. 

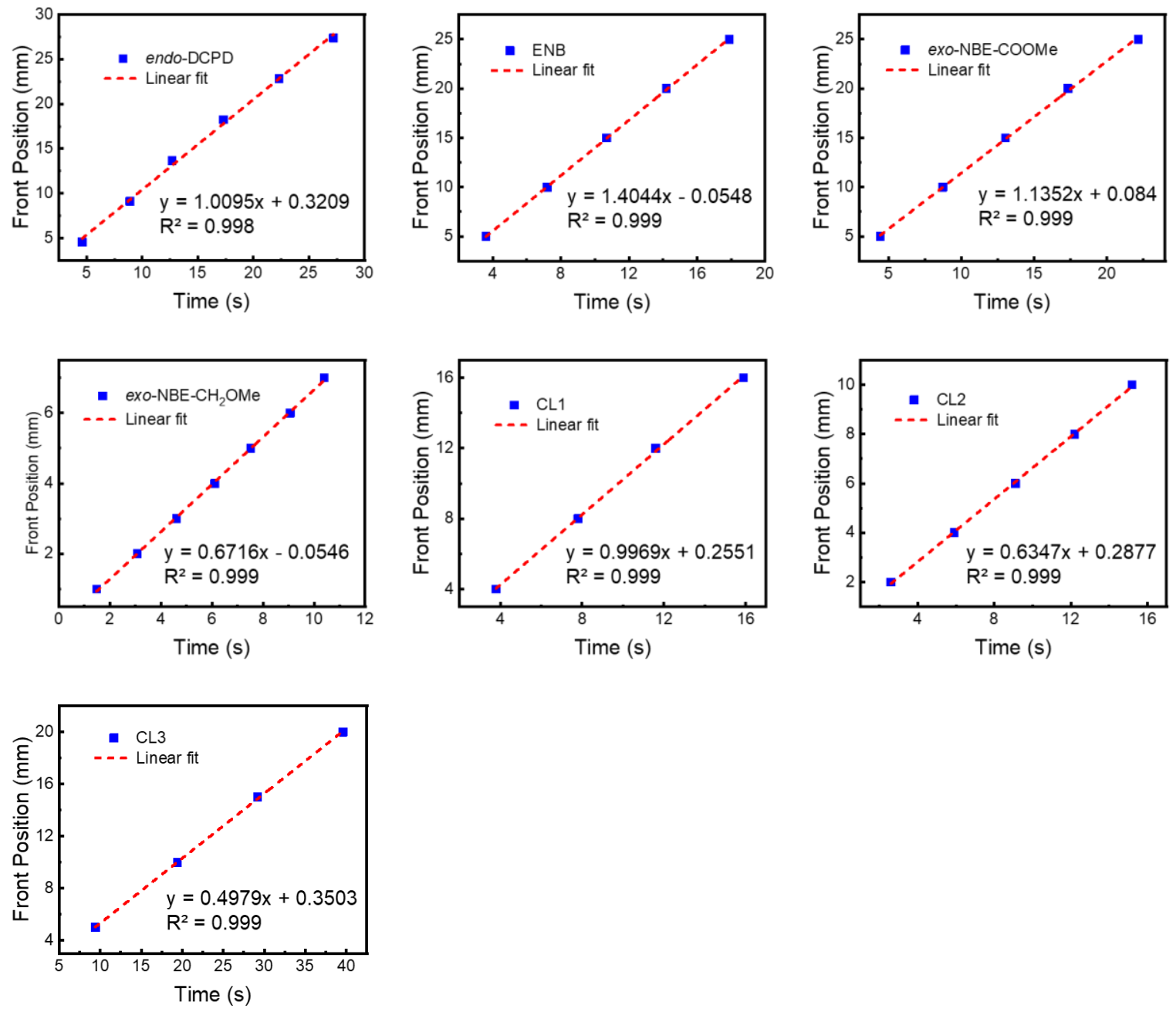

Figure S1. Front velocity of investigated monomers upon homopolymerization.

Table S1. Molecular weight, density and $[M]_{\text {neat }}$ of comonomers.

\begin{tabular}{cccccccc}
\hline Monomer & $\begin{array}{c}\text { endo- } \\
\text { DCPD }\end{array}$ & ENB & $\begin{array}{c}\text { exo-NBE- } \\
\text { COOMe }\end{array}$ & $\begin{array}{c}\text { exo-NBE- } \\
\mathrm{CH}_{2} \mathrm{OMe}\end{array}$ & CL1 & CL2 & CL3 \\
\hline $\begin{array}{c}\mathrm{MW} \\
(\mathrm{g} / \mathrm{mol})\end{array}$ & 132.21 & 120.19 & 152.19 & 138.21 & 244.33 & 302.37 & 330.42 \\
\hline $\begin{array}{c}\rho \\
(\mathrm{g} / \mathrm{mL})^{a}\end{array}$ & 0.99 & 0.89 & 1.08 & 0.94 & 1.10 & 1.15 & 1.14 \\
\hline $\begin{array}{c}{[M]_{\text {neat }}} \\
(\mathrm{mol} / \mathrm{L})^{b}\end{array}$ & 7.5 & 7.4 & 7.1 & 6.8 & 9.0 & 7.6 & 6.9 \\
\hline
\end{tabular}

${ }^{a}$ Density was measured three times and reported as the average value with the standard deviation less than $0.01 \mathrm{~g} / \mathrm{mL}$.

${ }^{b}[M]_{\text {neat }}$ is calculated as $\rho / \mathrm{MW}$ per $\mathrm{NBE} \mathrm{C}=\mathrm{C}$ bond. 


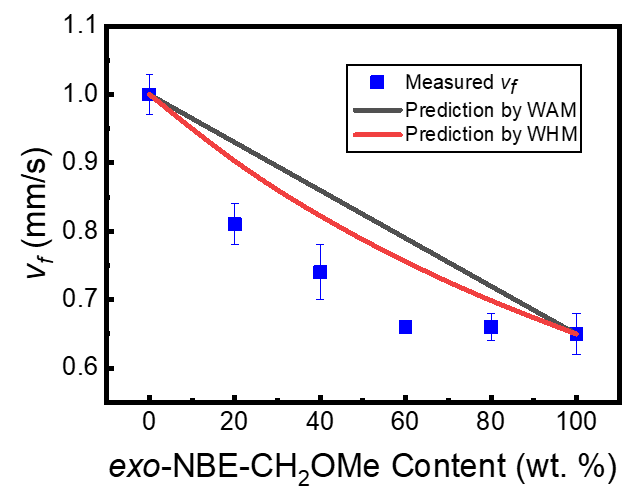

Figure S2. Front velocity of copolymerization of endo-DCPD and exo-NBE- $\mathrm{CH}_{2} \mathrm{OMe}$. WAM and WHM represent weighted arithmetic mean and weighted harmonic mean, respectively.

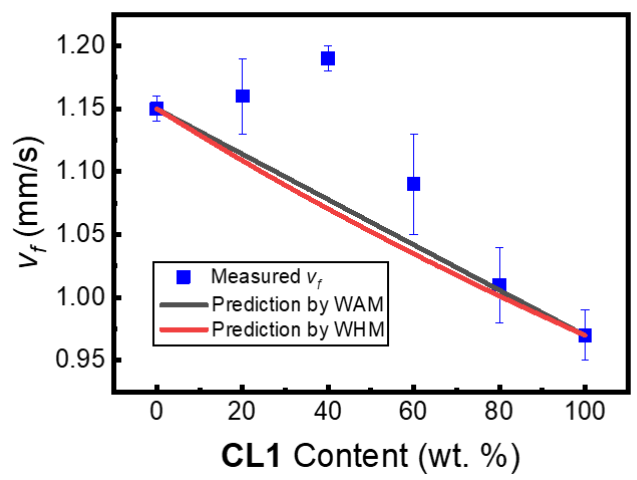

Figure S3. Front velocity of copolymerization of endo-DCPD and CL1 in toluene solution with the total norbornenyl $\mathrm{C}=\mathrm{C}$ concentration fixed at $7.11 \mathrm{M}$. The total volume of the solution and the norbornenyl $\mathrm{C}=\mathrm{C}$ were $0.505 \mathrm{~mL}$ and $3.59 \mathrm{mmol}$, respectively. WAM and WHM represent weighted arithmetic mean and weighted harmonic mean, respectively.

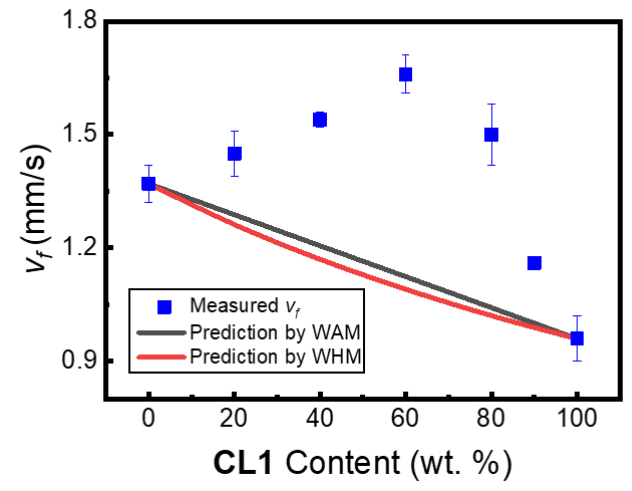

Figure S4. Front velocity of copolymerization of ENB and CL1. WAM and WHM represent weighted arithmetic mean and weighted harmonic mean, respectively. 


\section{DSC Characterization}

Determination of $\Delta \boldsymbol{H}_{\mathrm{p}}$ : After thoroughly mixing catalyst/phosphite solution with the monomers for FROMP experiments, 5-15 mg of the mixture was immediately transferred to a hermetic aluminum pan and placed in a pre-cooled DSC (to prevent simultaneous polymerization before data collection). Heat released data $\left(\Delta H_{\mathrm{p}}\right)$ was obtained by integrating the exothermic peak.
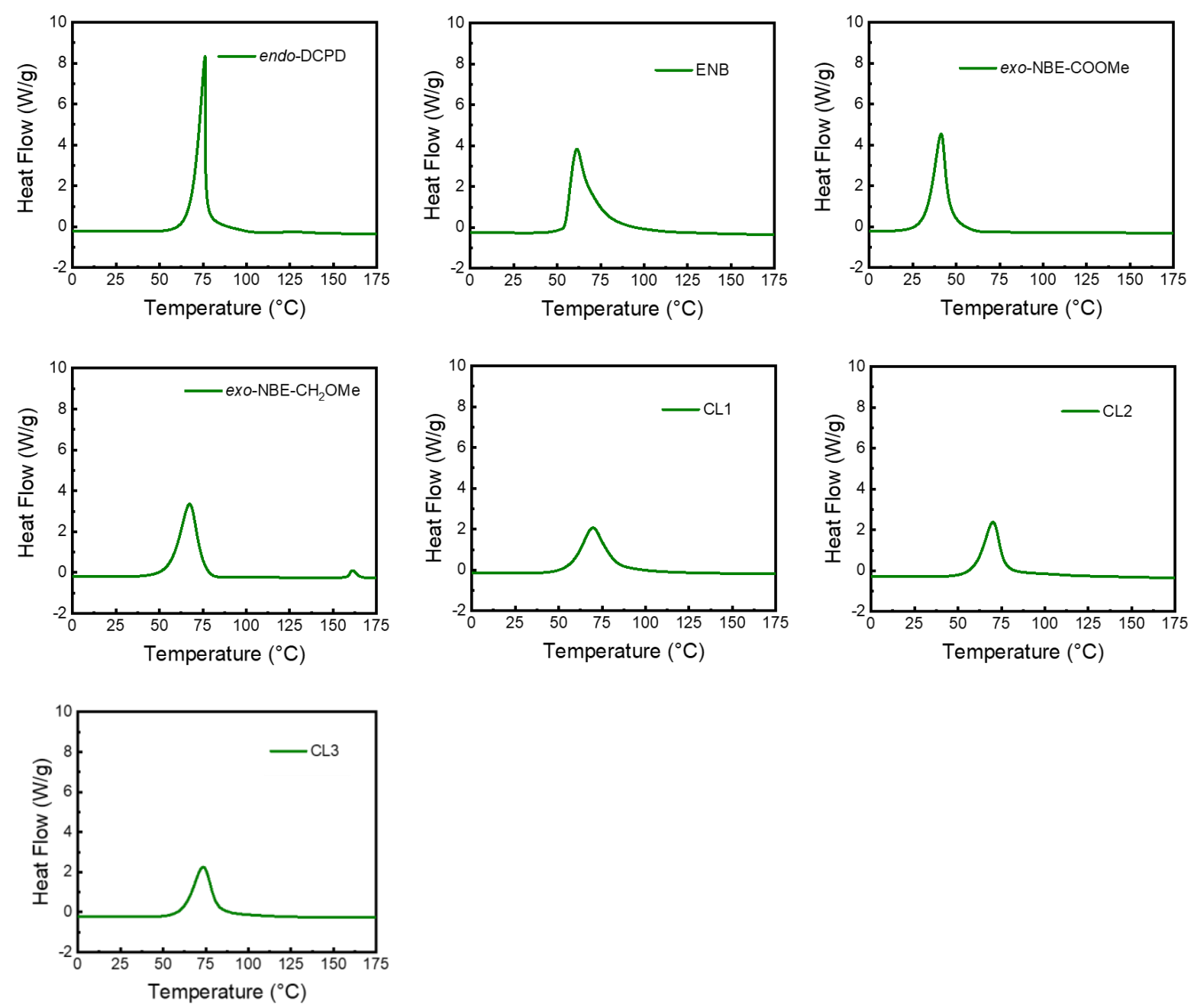

Figure S5. DSC traces of homopolymerization of each monomer. 

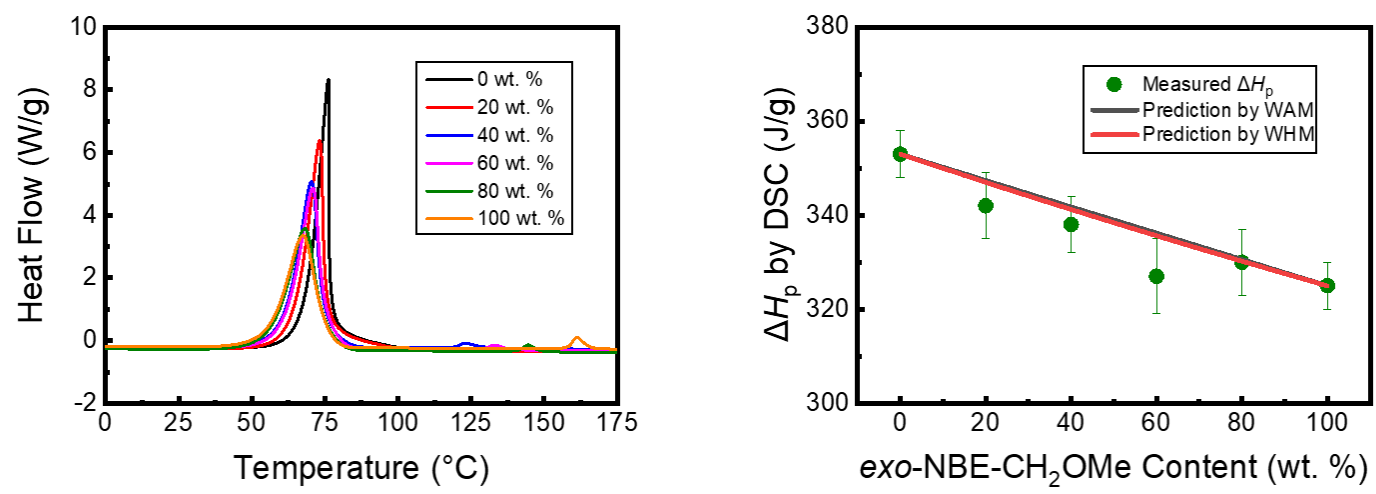

Figure S6. DSC traces (left) and heat released data (right) of copolymerization of endo-DCPD and exo-NBE- $\mathrm{CH} 2 \mathrm{OMe}$. WAM and WHM represent weighted arithmetic mean and weighted harmonic mean, respectively.
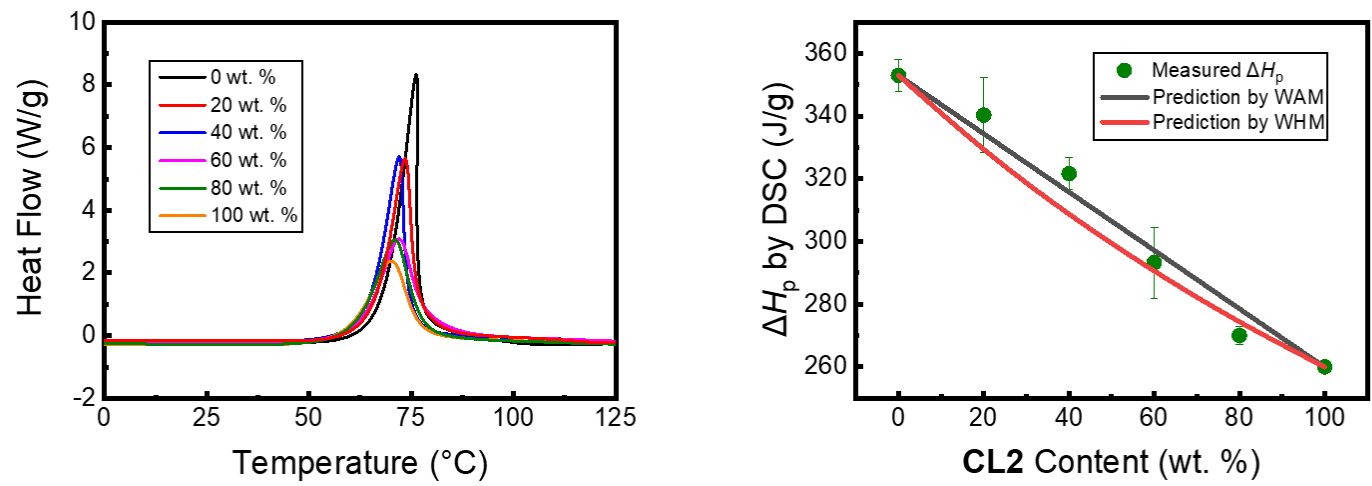

Figure S7. DSC traces (left) and heat released data (right) of copolymerization of endo-DCPD and CL2. WAM and WHM represent weighted arithmetic mean and weighted harmonic mean, respectively.
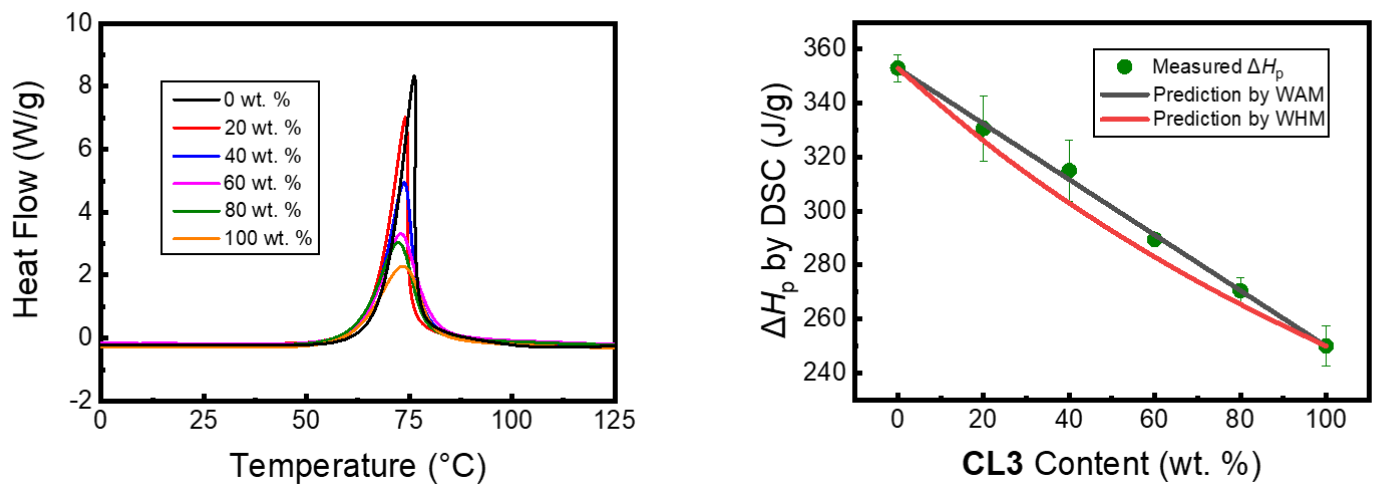

Figure S8. DSC traces (left) and heat released data (right) of copolymerization of endo-DCPD and CL3. WAM and WHM represent weighted arithmetic mean and weighted harmonic mean, respectively. 

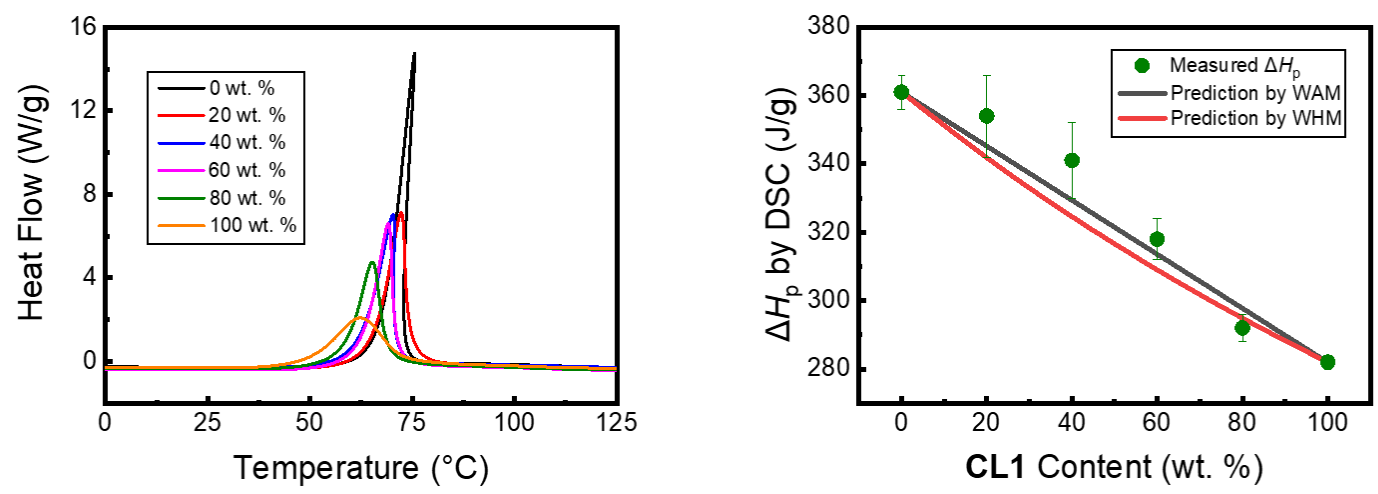

Figure S9. DSC traces (left) and heat released data (right) of copolymerization of endo-DCPD and CL1 in toluene solution with norbornenyl double bond concentration fixed at 7.1 M. WAM and WHM represent weighted arithmetic mean and weighted harmonic mean, respectively.
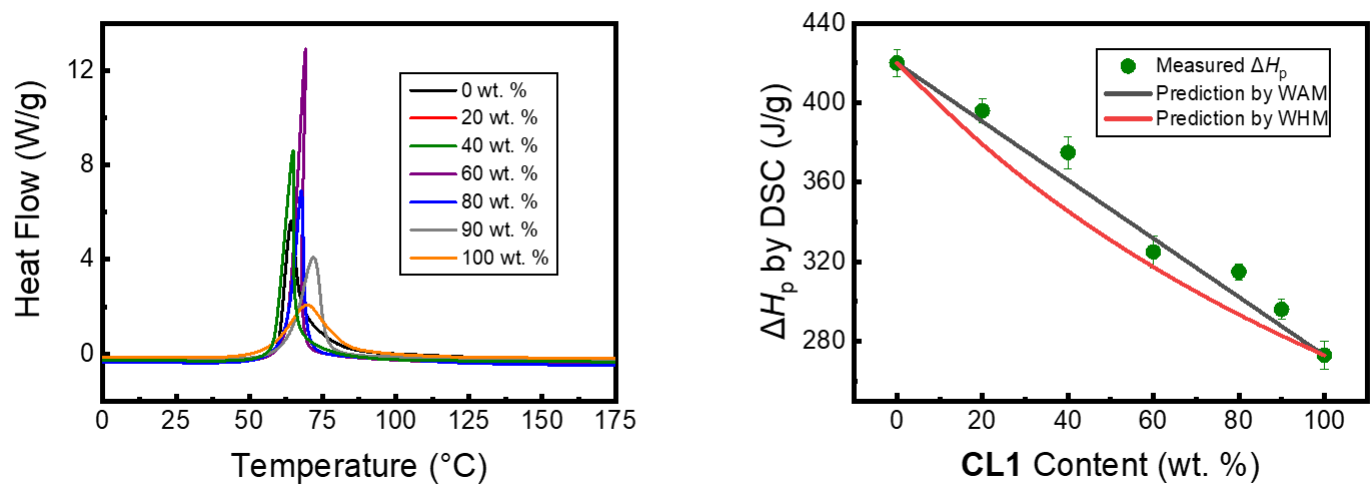

Figure S10. DSC traces (left) and heat released data (right) of copolymerization of ENB and CL1. WAM and WHM represent weighted arithmetic mean and weighted harmonic mean, respectively.

Glass transition temperature $\left(\boldsymbol{T}_{\mathrm{g}}\right)$ : The sample for $T_{\mathrm{g}}$ measurement after FROMP was taken from the part without the thermocouple. Then it was subjected to ramp scans from -50 to $200{ }^{\circ} \mathrm{C}$ at $10{ }^{\circ} \mathrm{C} / \mathrm{min}$. 


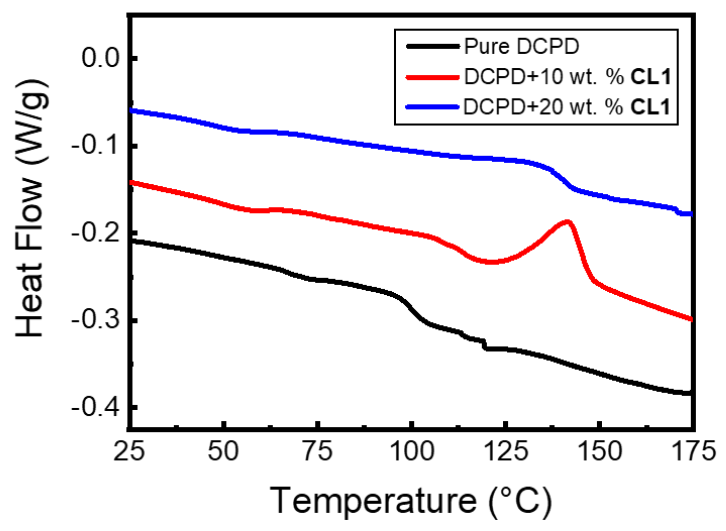

Figure S11. $T_{\mathrm{g}}$ of thermoset samples with different CL1 content.

\section{Concentration Dependence in FROMP}

FROMP experiments were conducted in the presence of $100 \mathrm{ppm}$ Grubbs II per NBE C=C, 1.0 equiv. $\mathrm{P}(\mathrm{OBu})_{3}$ and toluene as solvent to systematically vary the concentration.

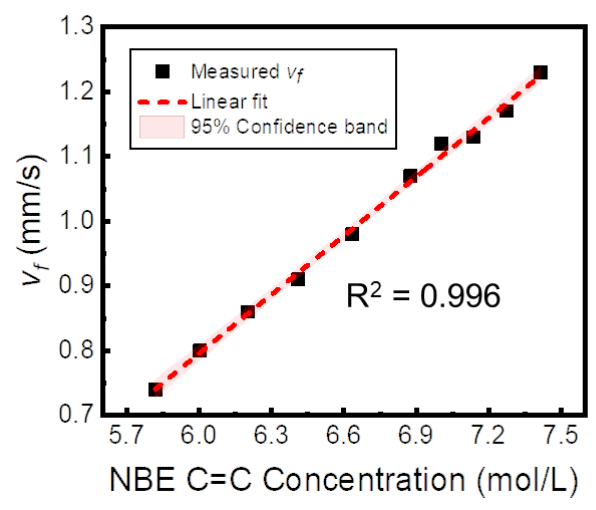

Figure S12. Concentration dependence of endo-DCPD in FROMP. A linear relationship was observed between $v_{f}$ and $\mathrm{NBE} \mathrm{C}=\mathrm{C}$ concentration. 

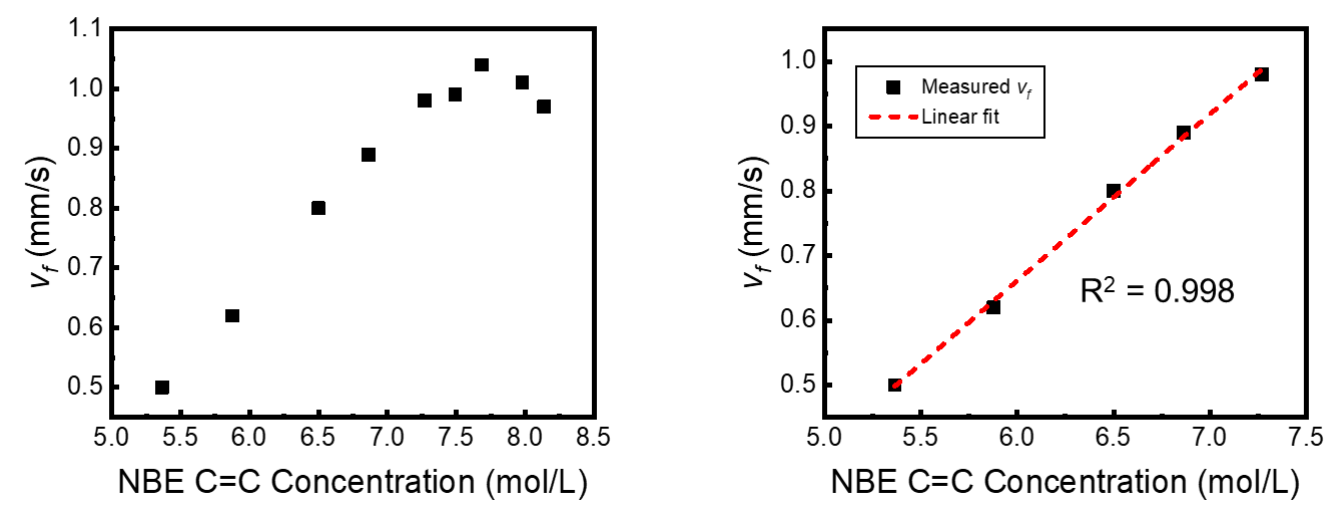

Figure S13. (Left) Concentration dependence of CL1 in FROMP. (Right) Linear relationship at lower NBE C=C concentration.

\section{VI. ${ }^{1} \mathrm{H}$ and ${ }^{13} \mathrm{C}$ NMR Spectra}

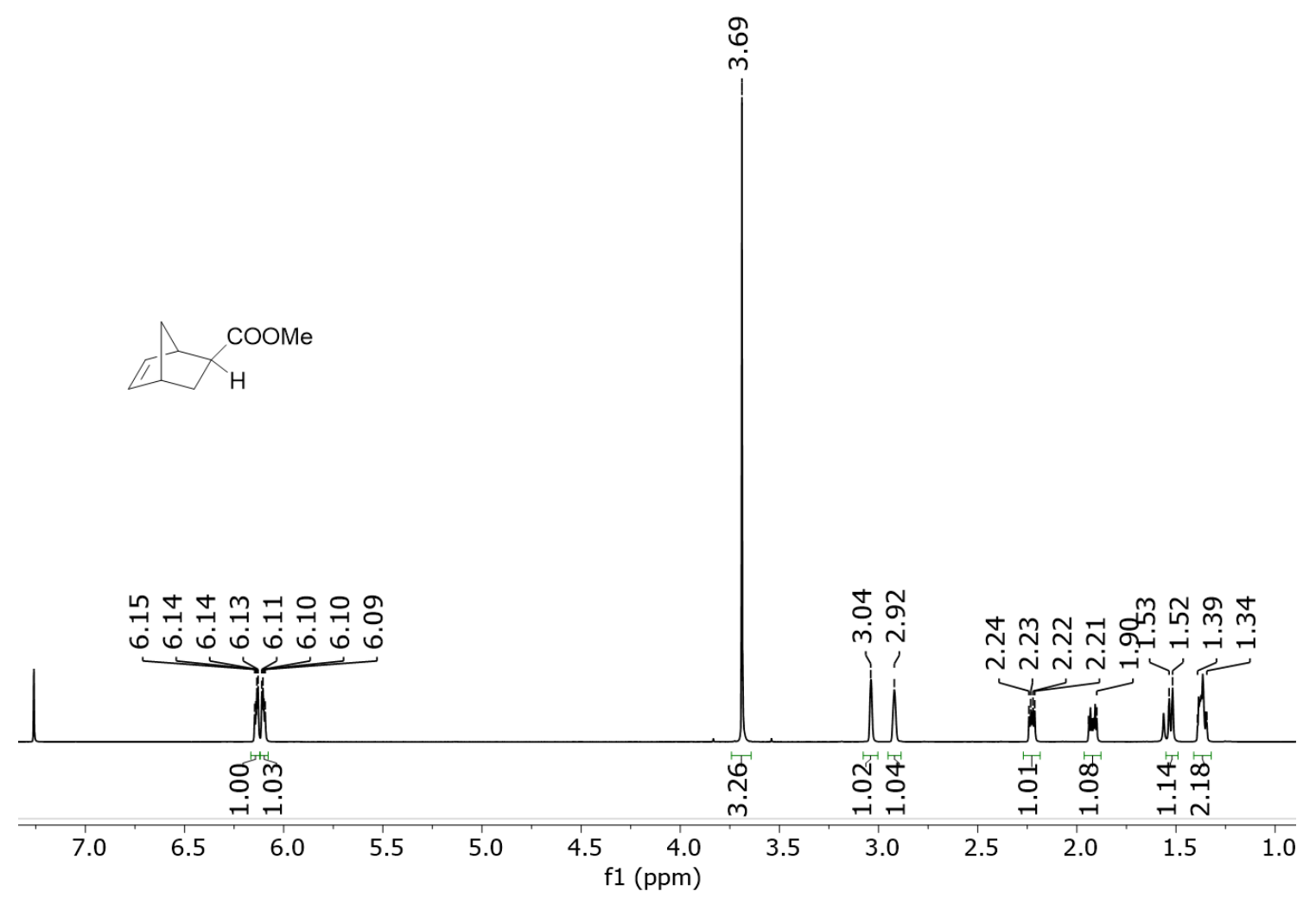




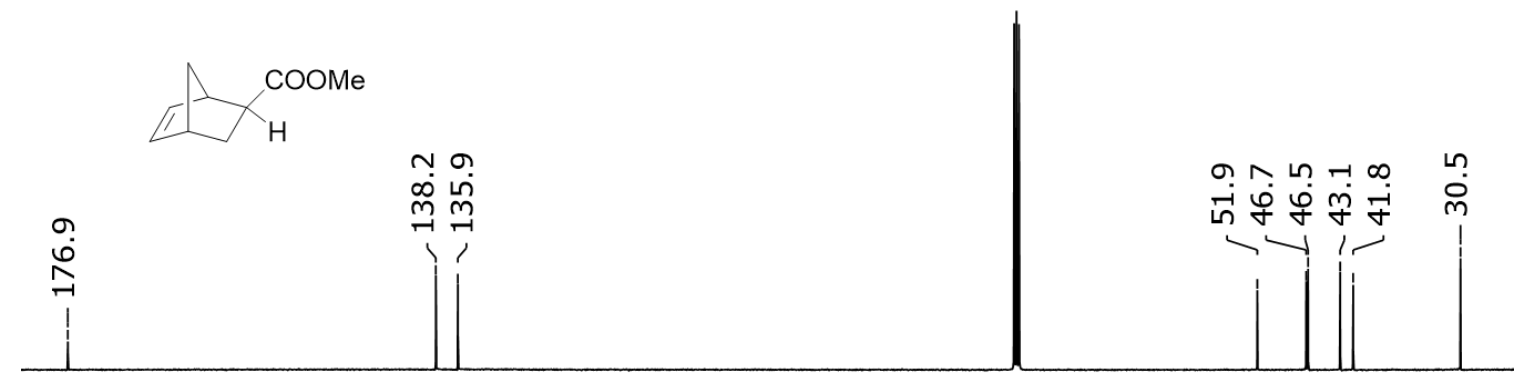

\begin{tabular}{|c|c|c|c|c|c|c|c|c|c|c|c|c|c|c|c|}
\hline 180 & 170 & 160 & 150 & 140 & 130 & 120 & 110 & $\begin{array}{r}100 \\
(\mathrm{ppm})\end{array}$ & 90 & 80 & 70 & 60 & 50 & 40 & 30 \\
\hline
\end{tabular}

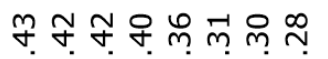

mं $\dot{m} \dot{m} \dot{m} \dot{m} m \dot{m} m$ m
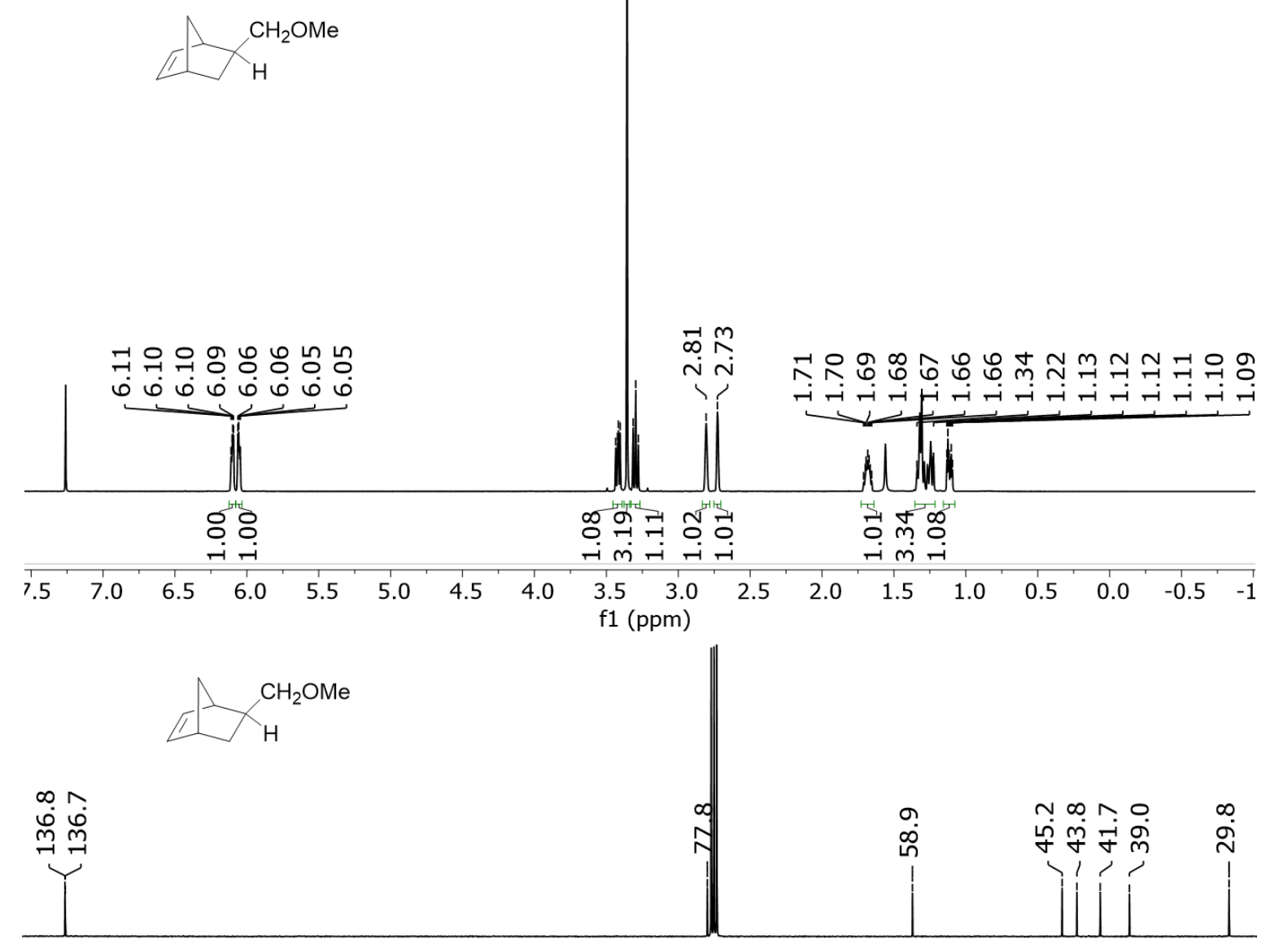

$\begin{array}{llllllllllllllllllllllllllll}40 & 135 & 130 & 125 & 120 & 115 & 110 & 105 & 100 & 95 & 90 & 85 & 80 & 75 & 70 & 65 & 60 & 55 & 50 & 45 & 40 & 35 & 30\end{array}$ 


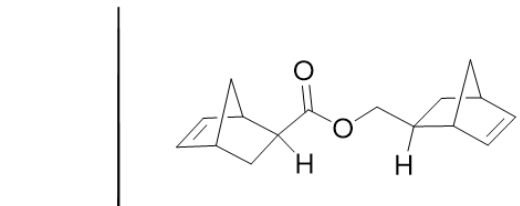

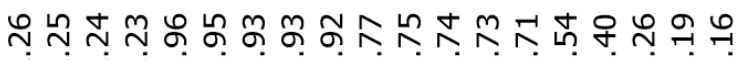
n n n n
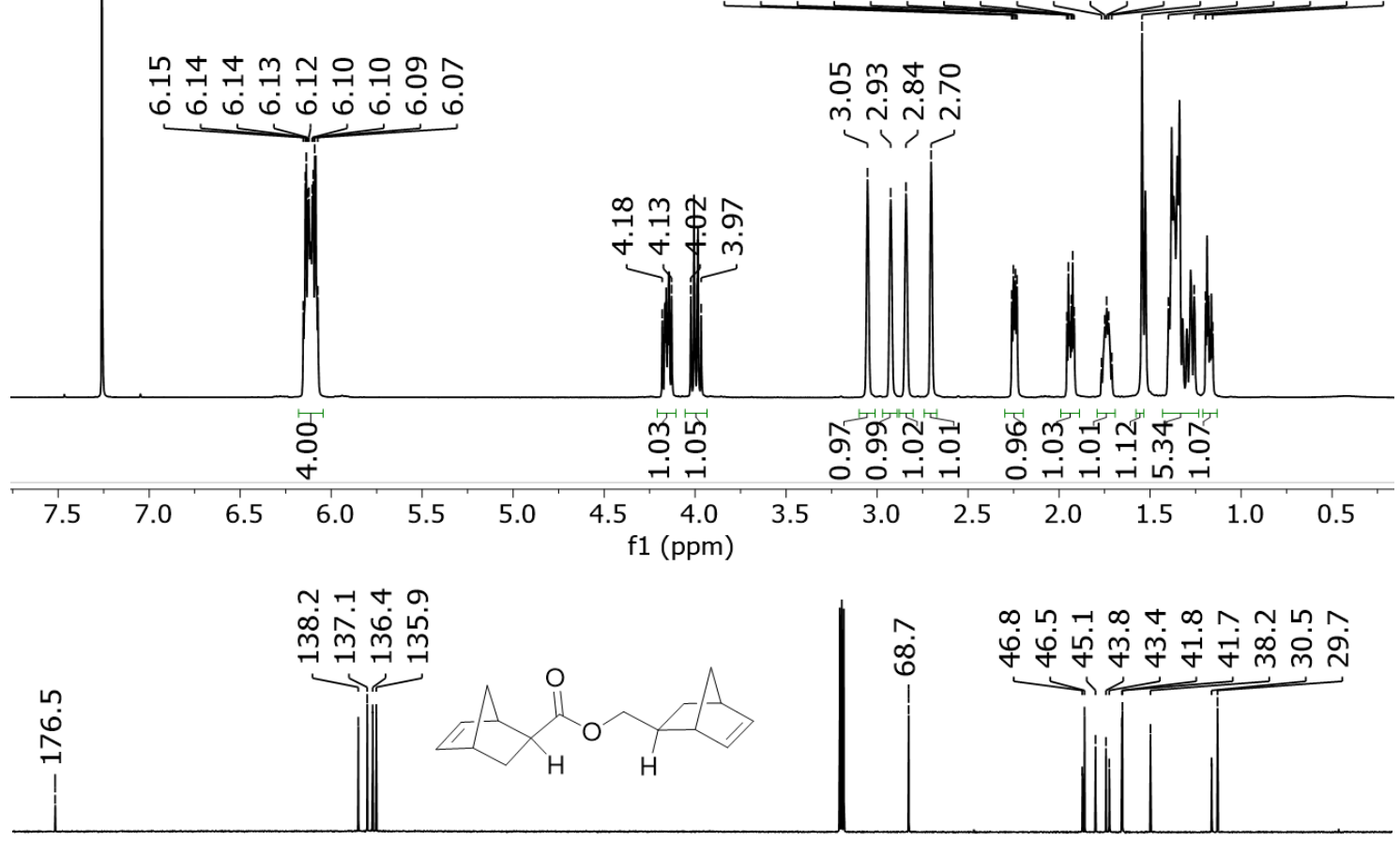

\begin{tabular}{|c|c|c|c|c|c|c|c|c|c|c|}
\hline $80 \quad 170$ & 16 & $0 \quad 150$ & 140 & 130 & 120 & 110 & 100 & s & 90 & 8 \\
\hline
\end{tabular}
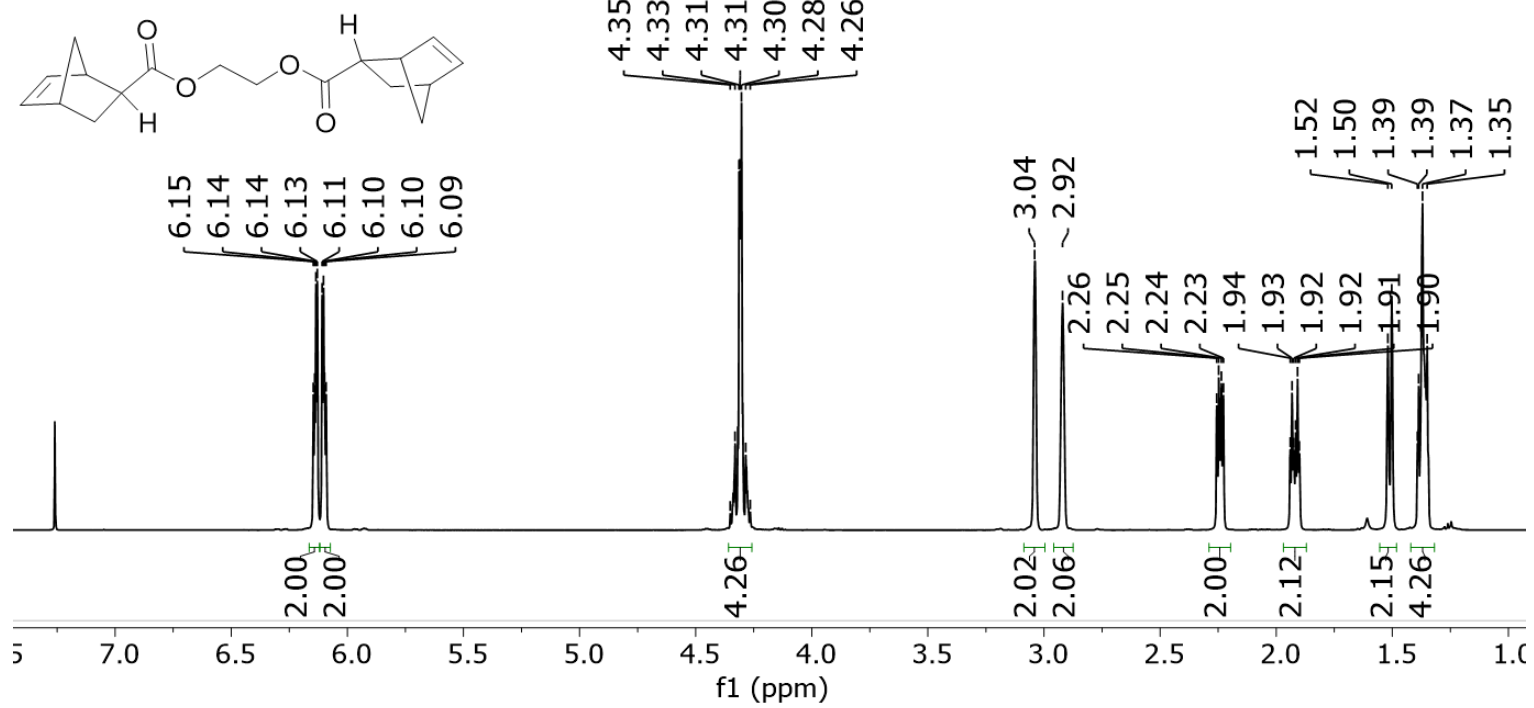


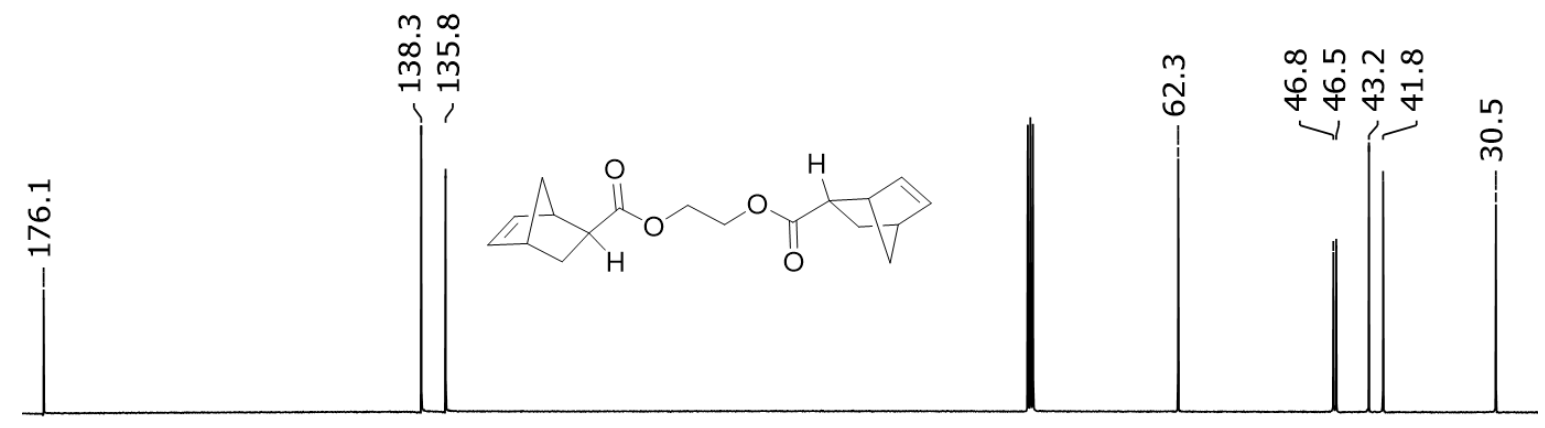

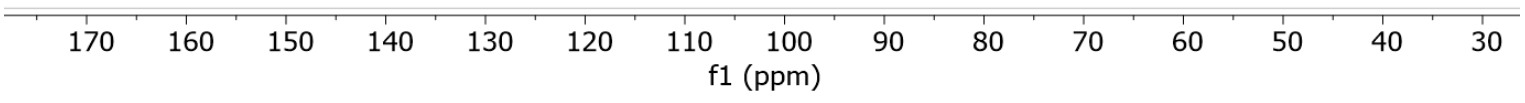
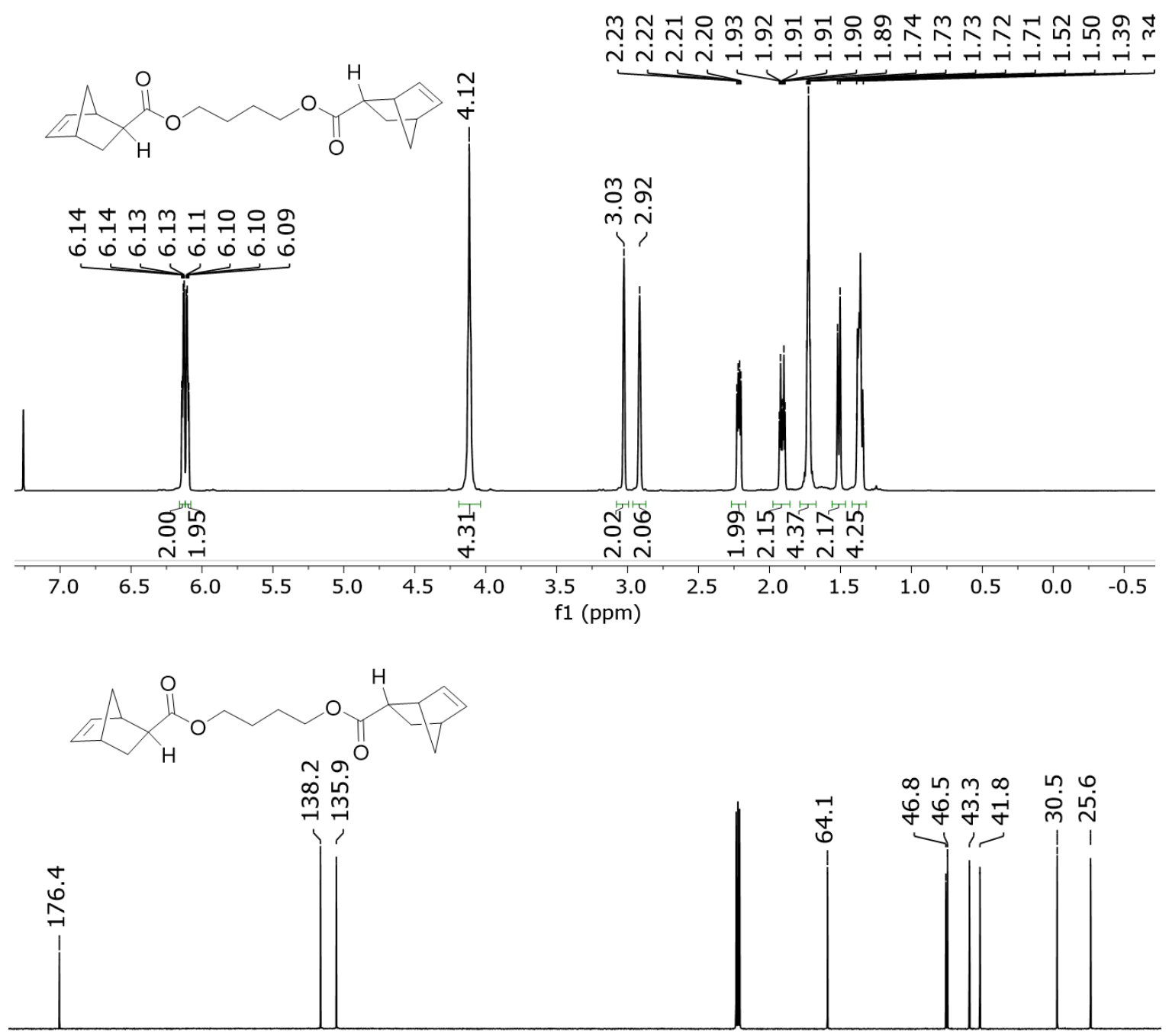

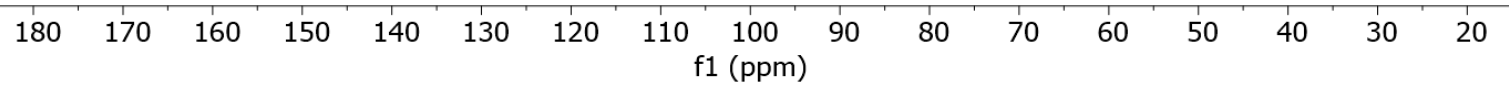




\section{References}

(1) Zha, Y.; Disabb-Miller, M. L.; Johnson, Z. D.; Hickner, M. A.; Tew, G. N. Metal-CationBased Anion Exchange Membranes. J. Am. Chem. Soc. 2012, 134, 4493-4496.

(2) Drouin, S. D.; Zamanian, F.; Fogg, D. E. Multiple Tandem Catalysis: Facile Cycling between Hydrogenation and Metathesis Chemistry. Organometallics 2001, 20, 5495-5497. 